\title{
Tuber Cinereum
}

National Cancer Institute

\section{Source}

National Cancer Institute. Tuber Cinereum. NCI Thesaurus. Code C33817.

A convex mass of grey matter located between the mammillary bodies and the optic

chiasma on the inferior surface of the hypothalamus, and from which the infundibulum extends to the posterior lobe of the hypophysis. 